\title{
Cross-Eurasian and altitudinal distribution of lotic mayflies - species with wider altitudinal ranges have narrower geographical distribution
}

\author{
Mikhail A. Beketov* \\ UFZ - Helmholtz Centre for Environmental Research, Permoserstrasse 15, 04318 Leipzig, Germany
}

Received 9 June 2009; Accepted 2nd September 2009

\begin{abstract}
The aim of the study was to test the hypothesis that patterns of cross-Eurasian longitudinal distribution of lotic mayflies are determined by species' ecological requirements and the presence of the West Siberian Lowland. In particular, the objective was to test whether this great lowland is an environmental barrier preventing longitudinal dispersal of the rheophilic (i.e., preferring fast-running highland waters), but not the potamophilic (i.e., preferring slow-current lowland waters) mayflies, as its entire territory contains no rapidly-flowing streams suitable for rheophilic species. This hypothesis was tested indirectly by comparison of altitudinal ranges of species characterised by different cross-Eurasian distribution patterns (mainly East Palaearctic and Transpalaearctic species distributed over the Asian part of Palaearctica and entire Palaearctica respectively). The material used for the analyses was collected in the centre of Eurasia, southwestern Siberia, Russia. The region covered both lowland and mountain territories. The studied biogeographical groups of mayflies have distinctly different altitudinal distribution: the Transpalaearctic species inhabit lowland watercourses only, while the East Palaearctic species inhabit the entire altitudinal range with most of the species preferring high elevations (on average $700 \mathrm{~m}$ a.s.1.). These results confirmed the stated hypothesis and showed that for most of the East Palaearctic (but not Transpalaearctic) species the West Siberian Lowland can be an environmental barrier preventing their westward dispersal and therefore precluding mixing of the East and West Palaearctic rheophilic faunas. However, possible alternative hypotheses cannot be ruled out, as altitudinal ranges of some of these species do not fall out of the elevation range of the West Siberian Lowland. Remarkably, the East Palaearctic species, which by definition have narrower distribution than the Transpalaearctic species, have broader altitudinal ranges than the Transpalaearctic species. This pattern is related to the altitudinal Rapoport effect recently detected for mayfly distribution over the river systems.
\end{abstract}

Key words: Altitude / ecological requirements / Ephemeroptera / macroecology / range

\section{Introduction}

A species' geographical distribution depends on many ecological, geographical, and historical factors. The most important among them are species' ecological requirements and dispersal abilities (Gaston, 1994; Ribera and Vogler, 2000; Hof et al., 2006), geographical barriers (Adams and Woodward, 1989; Bernatchez and Wilson, 1998), and evolutionary, geological, and climatic historical processes (Webb and Bartlein, 1992; Dynesius and Jansson, 2000). A complex interplay of these factors, but not any single factor, is currently thought to shape the geographical ranges of species (Lomolino et al., 2006;

\footnotetext{
*Corresponding author: mikhail. beketov@ufz.de
}

Whittaker et al., 2007; Hof et al., 2008; Bonada et al., 2009, and the references above).

Many freshwater species have broad geographical ranges despite the fact that freshwater habitats represent a system of discrete and unconnected sites (i.e., lakes, river basins) surrounded by terrestrial surface (Banarescu, 1990). Obviously, these species could only achieve wide distribution through active (e.g., aerial flight of merolimnic insects) and passive (e.g., by wind, animal vectors) dispersal over inhospitable habitats (Bilton et al., 2001 and references therein). Recently, species ranges of European aquatic beetles (Ribera and Vogler, 2000; Ribera et al., 2003) and European and North-American dragonflies (Hof et al., 2006) were conclusively correlated to dispersal propensity of these organisms, which in turn depends 


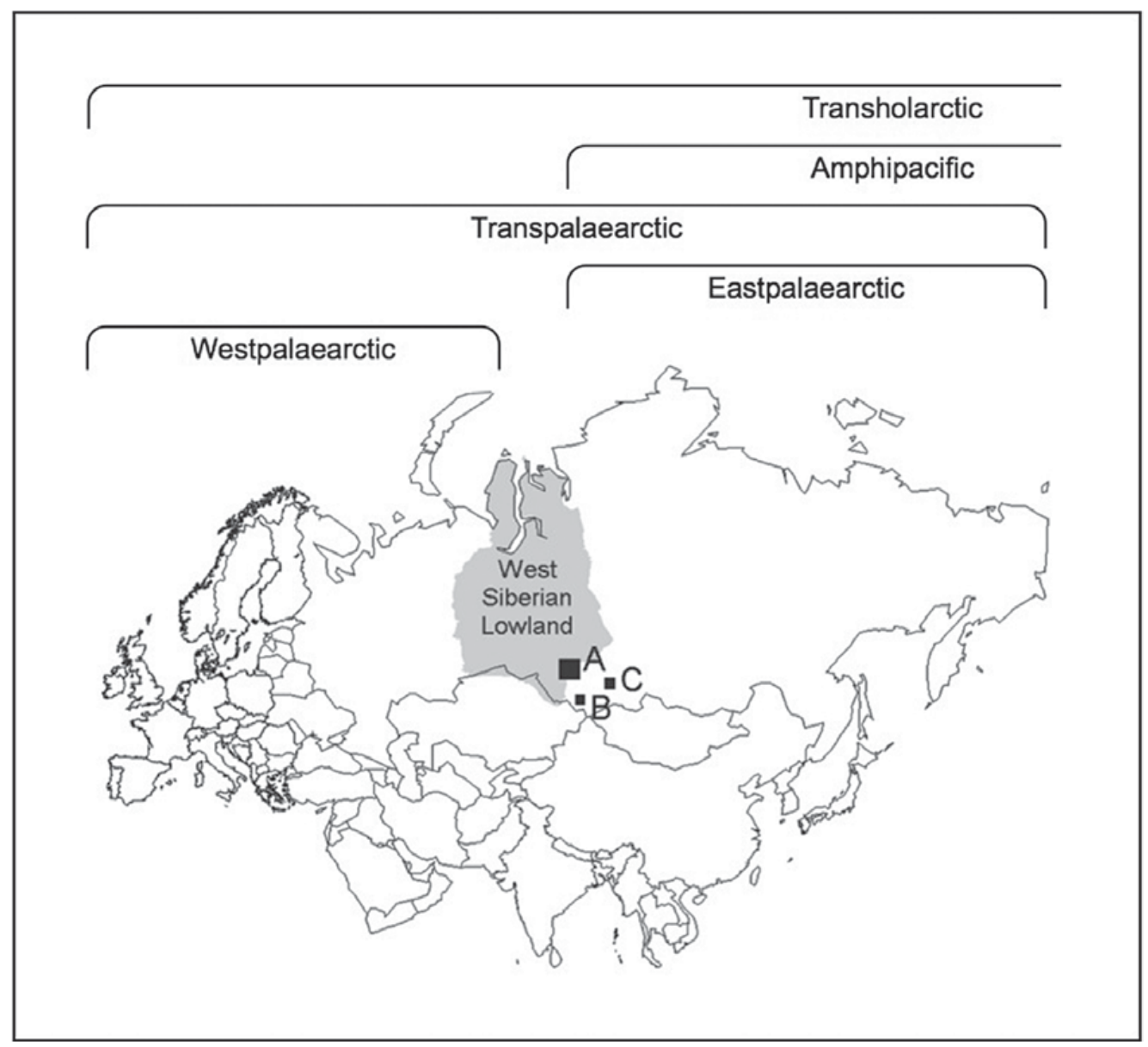

Fig. 1. Study areas: A - Novosibirsk Province, B - Altai Republic, and C - Khakassia; the West Siberian Lowland (grey area); and the major types of longitudinal ranges of palaearctic mayflies: West, East, Transpalaearctic, Amphipacific, and Transholarctic.

on their habitat preferences. Hof et al. (2006) also showed that the current distribution of dragonflies in Europe and North America is determined by an interplay of the species' dispersal propensity and the geographical orientation of mountain ranges. These studies empirically confirmed that dispersal propensity and location of environmental barriers are the crucial factors determining distribution of freshwater taxa.

Mayflies (Ephemeroptera) are an important and abundant component of lotic (flowing water) invertebrate communities (Ward, 1992). In the palaearctic region fauna and geographical distribution of mayflies have been studied patchily, largely in Europe (Euro-limpacs Consortium, 2006), and to a smaller degree in the Eurasian Far East (Tshernova et al., 1986; Tiunova, 2007), and in the geometric centre of Eurasia in southwestern Siberia (Beketov and Kluge, 2003; Beketov, 2005a, 2008a). Available knowledge indicates that many of the palaearctic mayflies have wide geographical distribution covering either the whole palaearctic region or half of it. These distributions can be classified into three major groups: Transpalaearctic - entire Palaearctica, West Palaearctic - European part of Palaearctica (also partly western Siberia, but it is questionable, see the Discussion), and East Palaearctic-Asian part of Palaearctica
(Kluge, 1997) (Fig. 1). Transholarctic and Amphipacific distributions are represented by small numbers of species.

Recent investigations by the author in southwestern Siberia extended the longitudinal ranges of many mayflies for thousands of kilometres, and showed that the West Siberian Lowland is a faunistic borderland separating East and West Palaearctic faunas (Fig. 1) (see also Novikova and Kluge, 1997). The evidence for this hypothesis is the high number of westernmost records of East Palaearctic species made at the eastern border of this lowland (23 species, study areas include both the plain and mountain territories, Fig. 1). Most of these East Palaearctic species are distributed over the entire great South-Siberian Mountain System, which extends from the eastern border of the West Siberia Lowland in the west (Beketov and Kluge, 2003; Beketov, 2004a, 2005a, 2005b, 2007) to the Pacific Ocean in the east (Tshernova et al., 1986; Kluge, 1997). In addition to these findings, six easternmost records of West Palaearctic species were made from the same area (e.g. the "classical" European species Ephemera vulgata was first found in Asia, Beketov and Kluge, 2003; see also Kluge, 1997; Beketov, 2004a). The same distribution patterns were also observed for caddisflies (Beketov, 2006) and stoneflies (Beketov, 2007). 
Previously, Novikova and Kluge (1997) proposed a hypothesis that may explain this fascinating pattern in over-continental distribution of mayflies and other aquatic insects. They proposed that the West Siberian Lowland (also known as West Siberian Plain, Fig. 1) is an environmental barrier preventing longitudinal dispersal of the rheophilic (i.e. preferring fast-running waters), but not the potamophilic mayflies (i.e. preferring lowland slowcurrent rivers) (also several standing-water species). This lowland is large (2.6 million $\mathrm{km}^{2}$-approximately onetenth of entire Eurasia, west-east width is $1900 \mathrm{~km}$ ), low (50-120 $\mathrm{m}$ a.s.1.) and flat territory having no rapidly flowing streams with stony bottoms typical for high altitudes and suitable for rheophilic species (Sokolov, 1952; Ioganzen, 1953; Rihter, 1963; Milkov and Gvozdetskii, 1976). In geological history, until the end of the tertiary period the West Siberian Lowland was a sea bottom, and its flat surface was made up of a thick layer of sediments (Sokolov, 1952; see also Lomolino et al., 2006). Hence, achievement of the wide Transpalaearctic distribution by mayflies became possible only after formation of this lowland as a dry territory. The species able to achieve such distribution should be potamophilic, as lowland watercourses are present over the entire palaearctic region including the West Siberian Lowland.

This hypothesis remained untested, as a direct test including monitoring of dispersing individuals is very difficult, if not impossible. The reason is not only technical difficulties in monitoring of migrating individuals (Bilton et al., 2001), but, to a higher degree, the fact that individual mayflies are most likely unable to migrate over distances larger than tens of kilometres (Hershey et al., 1993; Kovats et al., 1996; Winterbourn et al., 2007), and therefore they can only cross the West Siberian Lowland in several consecutive generations, reproducing in habitats within this lowland. Obviously, at present it is technically impossible to monitor such multi-generation dispersal. A possible but indirect way to test this hypothesis is to measure and compare ecological characteristics (e.g. altitudinal ranges) of species having different geographical attributes. Thus, as explained above, it is expected that Transpalaearctic species distributed over the entire Eurasia inhabit low-elevation watercourses and therefore can cross the West Siberian Lowland. In contrast, most of the West and East Palaearctic species are expected to inhabit high-elevation streams and therefore are unable to cross this great lowland. Information about altitudinal distribution of Trans-, West, and East Palaearctic groups of lotic mayflies recently obtained in southwestern Siberia from the altitudinal gradient $90-2200 \mathrm{~m}$ a.s.1. (i.e. from both the West Siberian Lowland at its eastern border and mountain territories to the East from this lowland; Beketov, 2009) makes such analysis feasible. Besides, available literature data can be used to control for possible biases associated with recording the species altitudinal distribution of widely (across-Eurasia) distributed species in a small part of their geographical range (present study sites) (for Europe see Euro-limpacs Consortium, 2006, for Asia see e.g. Kluge, 1997; Zaika, 2006).
The aim of the present study was to test the hypothesis that patterns of cross-Eurasian longitudinal distribution of lotic mayflies is determined by the West Siberian Lowland and species' ecological requirements. In particular, the objective was to test the statement that this lowland can be an environmental barrier preventing longitudinal dispersal of the rheophilic, but not the potamophilic mayflies, and therefore precluding mixing of the East and West Palaearctic rheophilic faunas. This hypothesis was tested indirectly by measuring and comparing altitudinal ranges of species characterised by different cross-Eurasian distribution patterns. Although altitude itself is not a factor directly affecting mayflies, altitudinal ranges were used as an integrative yet approximate measure of the species' "ecological position" in a river system, as key environmental factors (e.g. temperature, oxygen, bottom substrate) depend on the altitude (Allan, 1995; Beketov, 2008a; Jacobsen, 2008; for discussion on such dependences see Discussion), and determine structure of mayfly assemblages as a single dominant gradient (Beketov, 2008a).

\section{Material and methods}

\section{Study area}

The material analysed in the present study was collected in the geometric centre of Eurasia, southwestern Siberia, Russia. In particular, samples were taken in three regions: Novosibirsk Province, Altai Republic, and Khakassia (Fig. 1). Novosibirsk Province is situated in the southeast of the West Siberian Plain and mainly characterised by a flat relief with only the low mountains of Salairskii Kryazh (up to $502 \mathrm{~m}$ a.s.l.) in the southeast of the province. These low mountains are the westernmost component of the great South-Siberian Mountain System that extends from the eastern border of the West Siberia Plain to the Pacific Ocean. In contrast to Novosibirsk Province, the Altai Republic and Khakassia are predominantly characterised by mountainous relief with Altai and Western Sayany mountain systems respectively (also components of the great South-Siberian Mountain System). The majority of the mountains in these two regions are below $2000 \mathrm{~m}$ a.s.l. The climate of the area is moist continental, mid-latitude with cold winters and relatively warm summers. Mean July temperatures are 20, 12, and $16{ }^{\circ} \mathrm{C}$ in Novosibirsk Province, Altai Republic, and Khakassia respectively. Mean January temperatures are $-18,-18$, and $-20{ }^{\circ} \mathrm{C}$ respectively (extreme temperatures can reach $-40{ }^{\circ} \mathrm{C}$ ). Detailed description of the study area and the watercourses sampled can be found elsewhere (Beketov, 2008a).

\section{Data source and sampling}

The data set analysed here was obtained from a previous study (Beketov, 2009). This data set was created 
by random re-sampling of the large initial data set comprising 1189 samples and 55 species collected from 51 sites (data on presence/absence of species per site). Resampling was performed to avoid an influence of sample quantity on the analysed altitudinal ranges (disproportionally high number of samples at low elevations would increase number of low-elevation records and result in erroneous downward shift of the ranges). The entire altitudinal gradient (90-2200 $\mathrm{m}$ a.s.l) was divided into 100-m altitudinal bands, and the initial data set was once randomly re-sampled to obtain an equal number of samples ( 8 samples) per each altitudinal band (samplebased rarefaction without replacement, Gotelli and Colwell, 2001). The re-sampled data set used in the present analysis includes 136 samples, 42 sample sites, and 47 species (for details see Beketov, 2009).

Mayfly larvae were collected in watercourses covering the entire river continuum system from rithral to potamal zones, but excluding the crenal zone (Illies and Botosaneanu, 1963; for details see Beketov, 2008a). No mayfly larvae were found above $2200 \mathrm{~m}$ a.s.1. in the crenal zone. In the investigated region it is unlikely that at elevations below 90 or higher than $2200 \mathrm{~m}$ a.s.l. additional species can be found, because elevations around $100 \mathrm{~m}$ a.s.l. were already extensively sampled and lower elevations characterised by swampy territories and slow-current rivers has very poor mayfly fauna. Concerning high altitudes, samplings at elevations higher than $2200 \mathrm{~m}$ a.s.l. revealed absence of mayfly larvae, and as mentioned above, the majority of mountains in the region are below $2000 \mathrm{~m}$ a.s.l. Data from uncontaminated streams were considered only (for details see Beketov, 2004b, 2009; Beketov and Liess, 2008). Channel width ranged from 0.5 to $25 \mathrm{~m}$. Samples were taken by a D-frame net $(500 \mu \mathrm{m}$ mesh) from all the major stream habitat types present in a water body including stones and pebbles, submerged macrophytes, and fine sediments. Sampling area varied between 0.125 and $0.25 \mathrm{~m}^{2}$. Each sample constituted all mayfly larvae collected from the sampling area, but highly abundant species were not quantified in some samples. Therefore a species presence/absence table was created and species abundances were not analysed. Absolute altitude was measured by a GPS (e-Trex, Garmin, Olathe, USA) or maps.

\section{Biogeographical groups and taxonomy}

To describe cross-continental longitudinal patterns of species distribution, the species were classified into five main biogeographical groups (Fig. 1). These are: East Palaearctic (Asian part of Palaearctica), West Palaearctic (European part of Palaearctica and partly western Siberia, but see discussions below and in the Discussion section), Transpalaearctic (entire Palaearctica), Transholarctic (Palaeractica and Nearctica), and Amphipacific (northern Asia and North America) groups (Fig. 1). This raw classification does not reflect species' geographical ranges in detail, but rather characterises the distribution at macro-geographical spatial scale (over continents). This system was used previously to define the main biogeographical groups of mayflies (Kluge, 1997; Beketov and Kluge, 2003) and other aquatic insects (Beketov, 2006, 2007). Application of the term "West Palaearctic" to the species found in Asia (i.e., in the study area, Fig. 1) is questionable, as most of the "true West Palaearctic" species are distributed in Europe only. Nevertheless it is applied here, as it was used before (Kluge, 1997; Beketov and Kluge, 2003) to define species distributed in Europe and western Siberia, but not known from eastern Siberia and the Far East. The taxonomy used here is based on Kluge (1997). Abbreviated species names are used throughout the text, full species names are given in Table 1 .

\section{Data analysis}

To reveal whether the West Siberian Plain can be a barrier preventing westward distribution of the East Palaearctic species, the lower borders of altitudinal ranges of these species were compared with the elevations of this great plain (major territory at 50-120 m a.s.l., elevations up to $150-300 \mathrm{~m}$ a.s.l. at margins of the plain only, Sokolov, 1952). To further describe altitudinal distribution of species, mean and breadth of altitudinal range was calculated for each species. The mean was calculated as the arithmetic average of all altitudes at which a species was recorded. The breadth was calculated as the difference between highest and lowest altitudes inhabited by a species. Comparison of means and breadths of species altitudinal ranges between the biogeographical groups was performed by a non-parametric analysis of variance with Kruskal-Wallis test followed by a non-parametric multiple comparison test of the Behrens-Fischer type (Munzel and Hothorn, 2001). The non-parametric methods were selected because normality of distribution could not be credibly tested in small groups. Transholarctic and Amphipacific groups were excluded from this analysis, as each of these groups included one species only. Regression analysis for geographical and altitudinal ranges was not performed, as the biogeographical groups represent rather categorical than continuous data. Composition of the mayfly assemblage over the altitudinal gradient in terms of the biogeographical groups was described by calculating percentages of each group in the sums of species (not individuals) recorded from each 100-m altitudinal band. Transholarctic and Amphipacific groups were taken together. All statistical computations and graphics were made using the open-source software package $\mathrm{R}$, version 2.7 for Mac OS X (R Development Core Team, 2004).

\section{Results}

In total the analysed data set comprised 47 mayfly species belonging to 10 families (Table 1). Most of the species have East and Transpalaearctic types of 
Table 1. List of mayfly species analysed in the present study. Types of geographical distribution are coded as: TP - Transpalaearctic, EP - East Palaearctic, WP - West Palaearctic, A - Amphipacific, and TH - Transholarctic.

\begin{tabular}{|c|c|c|}
\hline Species & Distribution & Altitudinal range, $\mathrm{m}$ a.s.l. \\
\hline \multicolumn{3}{|l|}{ Baetidae } \\
\hline Baetis bacillus (Kluge, 1983) & EP & $131-445$ \\
\hline Baetis bicaudatus (Dodds, 1923) & A & $650-2200$ \\
\hline Baetis feles (Kluge, 1980) & EP & $337-950$ \\
\hline Baetis fuscatus (Linnaeus, 1761) & $\mathrm{TP}$ & $120-650$ \\
\hline Baetis pseudothermicus (Kluge, 1983) & EP & $135-1332$ \\
\hline Baetis sibiricus (Kazlauskas, 1963) & EP & $240-496$ \\
\hline Baetis tricolor (Tshernova, 1928) & $\mathrm{TP}$ & $120-496$ \\
\hline Baetis tuberculatus (Kazlauskas, 1963) & EP & $120-334$ \\
\hline Baetis ursinus (Kazlauskas, 1963) & EP & $120-470$ \\
\hline Baetis vernus (Curtis, 1834) & $\mathrm{TP}$ & $120-496$ \\
\hline Baetis sp. Rhodobaetis (Jacob, 2003) & unclear & $1278-1700$ \\
\hline Baetis sp. (vernus group) & unclear & $135-204$ \\
\hline Baetis sp. (fuscatus group) & unclear & $919-925$ \\
\hline Cloeon bifidum (Bengtsson, 1912) & $\mathrm{TP}$ & $120-196$ \\
\hline Cloeon dipterum (Linnaeus, 1761) & $\mathrm{TP}$ & $120-184$ \\
\hline Cloeon macronyx (Kluge \& Novikova, 1992) & $\mathrm{TP}$ & $120-184$ \\
\hline Cloeon simile (Eaton, 1870 ) & $\mathrm{TP}$ & $120-135$ \\
\hline \multicolumn{3}{|l|}{ Caenidae } \\
\hline Brachycercus harrisella (Curtis, 1834) & $\mathrm{TP}$ & $120-184$ \\
\hline Caenis horaria (Linnaeus, 1758) & TP & $120-196$ \\
\hline Caenis miliaria (Tshernova, 1952) & EP & $184-284$ \\
\hline Caenis pseudorivulorum (Keffermuller, 1960) & WP & $96-403$ \\
\hline \multicolumn{3}{|l|}{ Ephemerellidae } \\
\hline Ephemerella aurivillii (Bengtsson, 1908) & $\mathrm{TH}$ & $135-1700$ \\
\hline Ephemerella ignita (Poda, 1761) & $\mathrm{TP}$ & $96-496$ \\
\hline Ephemerella lenoki (Tshernova, 1952) & $\mathrm{EP}$ & $120-445$ \\
\hline Ephemerella lepnevae (Tshernova, 1949) & EP & $145-1332$ \\
\hline Ephemerella nuda (Tshernova, 1949) & EP & $919-1700$ \\
\hline Ephemerella triacantha (Tshernova, 1949) & $\mathrm{EP}$ & $135-1700$ \\
\hline \multicolumn{3}{|l|}{ Heptageniidae } \\
\hline Heptagenia flava (Rostock, 1878) & $\mathrm{TP}$ & $96-387$ \\
\hline Heptagenia fuscogrisea (Retzius, 1783) & $\mathrm{TP}$ & $120-120$ \\
\hline Heptagenia sulphurea (Müller, 1776) & $\mathrm{TP}$ & $96-445$ \\
\hline Ecdyonurus abracadabrus (Kluge, 1983) & EP & $131-445$ \\
\hline Ecdyonurus joernensis (Bengtsson, 1909) & $\mathrm{TP}$ & $120-441$ \\
\hline Rhithrogena cava (Ulmer, 1927) & EP & $445-2200$ \\
\hline Rhithrogena sp. (hirasana?) (Imanishi, 1935) & EP & $1278-2200$ \\
\hline Rhithrogena lepnevae (Brodsky, 1930) & $\mathrm{EP}$ & $131-470$ \\
\hline Epeorus alexandri (Kluge et Tiunova, 1989) & EP & $950-1050$ \\
\hline Epeorus maculatus (Tshernova, 1949) & $\mathrm{EP}$ & $1278-1700$ \\
\hline Epeorus pellucidus (Brodsky, 1930) & $\mathrm{EP}$ & $96-950$ \\
\hline \multicolumn{3}{|l|}{ Ephemeridae } \\
\hline Ephemera orientalis (McLachlan, 1875) & $\mathrm{EP}$ & $120-204$ \\
\hline Ephemera vulgata (Linnaeus, 1758) & WP & $120-184$ \\
\hline \multicolumn{3}{|l|}{ Isonychiidae } \\
\hline Isonychia ussurica (Bajkova, 1970) & EP & $121-221$ \\
\hline \multicolumn{3}{|l|}{ Leptophlebiidae } \\
\hline Leptophlebia chocolata (Imanishi, 1937) & $\mathrm{EP}$ & $950-1050$ \\
\hline Leptophlebia marginata (Linnaeus, 1768) & WP & $109-109$ \\
\hline Leptophlebia submarginata (Stephens, 1835) & WP & $96-184$ \\
\hline \multicolumn{3}{|l|}{ Polymitarcyidae } \\
\hline Ephoron virgo (Olivier, 1791) & WP & $120-184$ \\
\hline \multicolumn{3}{|l|}{ Potamanthidae } \\
\hline Potamanthus luteus (Linnaeus, 1767) & $\mathrm{TP}$ & $109-184$ \\
\hline \multicolumn{3}{|l|}{ Ameletidae } \\
\hline Ameletus sp.* & EP & $445-2200$ \\
\hline
\end{tabular}

* Group of hardly distinguishable East Palaearctic Ameletus species (Kluge, 2007). 


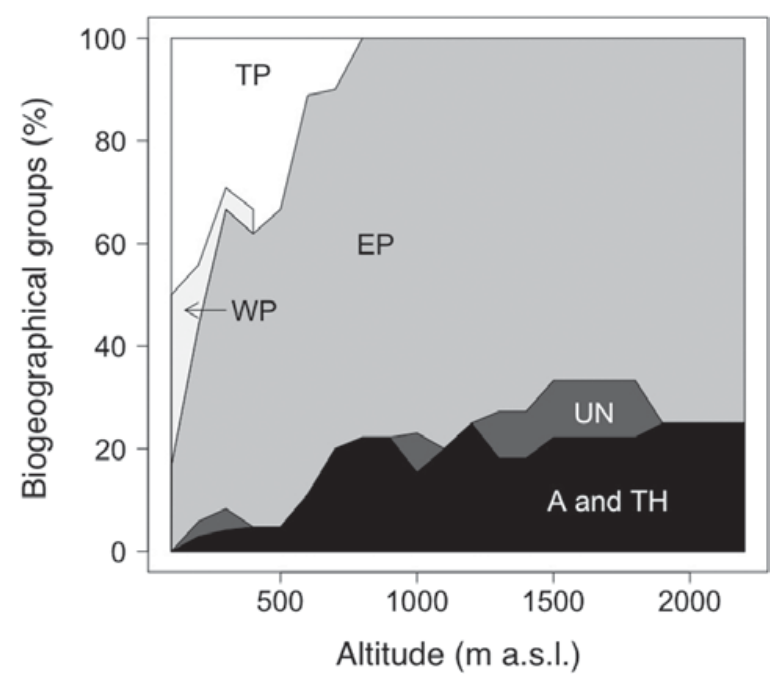

Fig. 2. Composition of the mayfly assemblage in terms of biogeographical groups along the altitudinal gradient $(\%$ of each group in the sum of species recorded from a $100-\mathrm{m}$ altitudinal band). Biogeographical groups are coded as: WP West Palaearctic, TP - Transpalaearctic, EP - East Palaearctic, A and $\mathrm{TH}-$ Amphipacific and Transholarctic, and UN - unclear distribution.

geographical distribution -22 and 15 species respectively. Other geographical groups included lower numbers of species: West Palaearctic-5 (not 6 as mentioned in the Introduction, as 1 species was not captured during the re-sampling), Transholarctic -1 (E. aurivillii), and Amphipacific - 1 (B. bicaudatus). Distribution patterns of the three Baetis species identified to the subgenus or species-group levels were defined as unclear (Table 1).

Composition of the mayfly assemblage in terms of biogeographical groups consistently changed along the altitudinal gradient (Fig. 2). Trans- and West Palaearctic species dominated at elevations below $200 \mathrm{~m}$ a.s.1. Proportion of these species drastically decreased with increase in altitude, and no such species were found at elevations above $700 \mathrm{~m}$ a.s.1 (Fig. 2). In contrast, proportion of East Palaearctic species increased with increase in altitude, and at elevations above $700 \mathrm{~m}$ a.s.1 these species accounted for $67-78 \%$ of the entire assemblage (Fig. 2). The two species having Transholarctic and Amphipacific distribution accounted for $0-25 \%$ (Fig. 2). Percentage of the species with unclear distribution varied from 0 to $11 \%$ (Fig. 2).

Comparison of the lower borders of species altitudinal ranges with the elevations of the West Siberian Plain (50$120 \mathrm{~m}$ a.s.l.) showed that only 5 out of 22 East Palaearctic species have the lower borders of their altitudinal ranges below or equal to $120 \mathrm{~m}$ a.s.l. These are E. pellucidus, B. tuberculatus, B. ursinus, E. lenoki, and E. orientalis (full names and altitudinal ranges are in Table 1). In contrast, all Trans- and West Palaearctic species had such lowest borders below or equal $120 \mathrm{~m}$ a.s.l. (Table 1).

To further understand difference in altitudinal distribution of the considered biogeographical groups, means
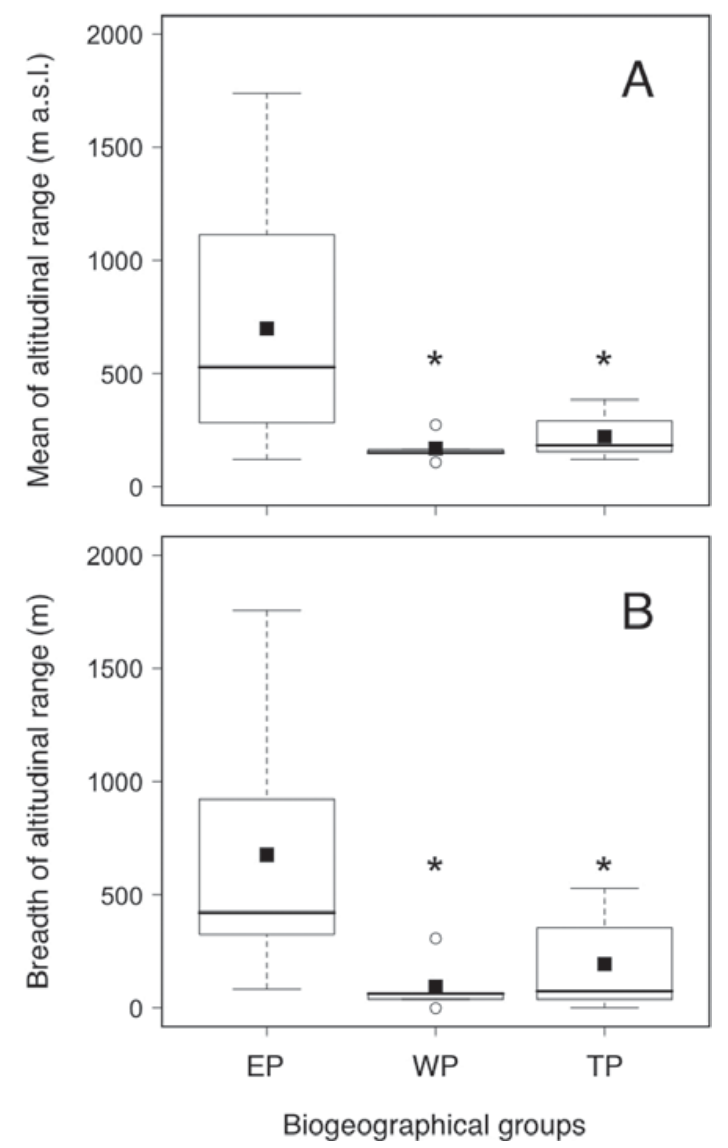

Fig. 3. Box-and-whisker plots of mean altitudinal ranges (A) and breadths of altitudinal ranges (B) of mayflies from East Palaearctic (EP), West Palaearctic (WP), and Transpalaearctic (TP) biogeographical groups. Asterisks indicate groups with insignificantly $(P>0.05)$ different medians (Kruskal-Wallis test with Behrens-Fischer multiple comparison test).

and breadths of species altitudinal ranges were compared. Both the Trans- and West Palaearctic groups had narrow gradients of species altitudinal ranges, with most of the species having means of altitudinal ranges $<300 \mathrm{~m}$ a.s.l. (Fig. 3A, only B. fuscatus has mean altitudinal range $385 \mathrm{~m}$ a.s.l.). In contrast, means of altitudinal ranges of East Palaearctic species ranged from 162 to $1739 \mathrm{~m}$ a.s.l with most of the species $(86 \%, 19$ out of 22 species) having means of altitudinal ranges $>300 \mathrm{~m}$ a.s.l. (average per-group elevation $700 \mathrm{~m}$ a.s.l., Fig. 3A). Comparison of the three biogeographical groups by Kruskal-Wallis test followed by Behrens-Fisher test revealed significant $(P<0.05)$ differences between the East Palaearctic group and both the Trans- and West Palaearctic groups. However, no significant difference $(P>0.05)$ was found between the Trans- and West Palaearctic groups (Fig. 3A).

Breadth of species altitudinal ranges in the East Palaearctic group varied from 84 to $1755 \mathrm{~m}$ (Fig. 3B). In the Trans- and West Palaearctic groups the breadths ranged from 0 to 530 and from 0 to $307 \mathrm{~m}$ respectively (Fig. 3B). Comparison of the three biogeographical groups 
showed that the East Palaearctic group differed significantly from both the Trans- and West Palaearctic groups $(P<0.05)$, while the Trans- and West Palaearctic groups did not significantly differ from each other $(P>0.05$, Kruskal-Wallis and Behrens-Fisher tests, Fig. 3B).

\section{Discussion}

\section{Species' geographical distribution, ecological requirements, and the West Siberian Lowland}

The present analysis revealed that the studied biogeographical groups of mayflies have distinctly different altitudinal distribution over the river continuum: the Trans- and West Palaearctic species inhabit lowland watercourses only, while the East Palaearctic species inhabit the entire altitudinal range, but predominantly relatively high elevations. These results confirm the hypothesis by Novikova and Kluge (1997) and show that for most of the East Palaearctic species the West Siberian Lowland can be an environmental barrier preventing their westward dispersal, and therefore determining their East Palaearctic distribution and preventing mixing of the East and West Palaearctic rheophilic faunas. Nevertheless, altitudinal ranges of 5 out of 22 recorded East Palaearctic species do not fall out of the elevation range of the West Siberian Lowland, as their lower altitudinal borders are below or equal to $120 \mathrm{~m}$ a.s.1. Therefore possible alternative hypotheses explaining distribution of these species cannot be ruled out. Obviously, westward dispersal of these species may be restricted by some altitudeindependent environmental factors (e.g., high salinity or extreme winter oxygen deficiency in the southern and northern parts of the West Siberian Lowland respectively). Additionally, some historical factors (e.g., glaciation, Ehlers and Gibbard, 2007) could contribute to the currently observed distributions, yet understanding of such factors is beyond the scope of the present study.

As mentioned in the Introduction, the majority of East Palaearctic species are distributed longitudinally over the entire great South-Siberian Mountain System, which extends from the eastern border of the West Siberian Lowland to the Pacific Ocean. This longitudinal geographical distribution fits the altitudinal patterns revealed in the present study (Figs. 2 and 3). In contrast to most of the East Palaearctic species, the Transpalaearctic species have the potamophilic ecological characteristic required to cross the West Siberian Lowland and achieve a crosscontinental distribution. As mentioned in the Introduction, mayflies are unable to fly over distances larger than tens of kilometres, and to cross the West Siberian Lowland the mayflies should be able to reproduce in aquatic habitats therein (i.e., be potamophilic).

The records of six West Palaearctic species from the eastern margin of the West Siberian Lowland suggest that this lowland cannot be a barrier precluding their longitudinal distribution, as they are found at both sides of the lowland (i.e., in Europe (e.g., Kluge, 1997) and in the study area, Fig. 1). This biogeographical observation is explicitly supported by the altitudinal distribution of these species as shown here, these species inhabit low elevations only (Figs. 2 and 3). Presumably, these species may actually be distributed much further to the East and be Transpalaearctic. Absence of records of these species from the eastern Siberia may be due to the very scarce investigations in this region. In general, the use of term "West Palaearctic" for the species found in Asia is questionable; it is applied here because it has previously been used for the species distributed in Europe and western Siberia (Kluge, 1997; Beketov and Kluge, 2003). Further investigations in eastern Siberia are required to clarify actual distribution of these species.

Latitudinal distribution of aquatic insects in East Palaearctica and Eastern Europe is poorly studied (but see Brodsky, 1980; Novikova and Kluge, 1997; Beketov, 2008b), and it remains unclear whether the territories to the north and south from the Western Siberian Lowland can provide passways connecting West and East Palaearctic faunas of mayflies.

\section{Breadth of geographical and altitudinal ranges - remarkable negative dependence}

An intriguing finding of the present study is that the East Palaearctic mayfly species, which by definition have narrower geographical distribution than the Transpalaearctic species (Fig. 1), have much broader altitudinal ranges (Fig. 3B). The broad altitudinal ranges imply broad ranges of the key environmental factors such as temperature and dissolved oxygen, as these factors strictly (yet non-linearly) depend on the altitude (Allan, 1995; Beketov, 2008a; Jacobsen, 2008). Such dependence is also valid for other factors such as current velocity and character of bottom substrate, but with much less accuracy, as these parameters are also influenced by local landscape characteristics. Thus, for the region investigated (including the sample sites considered here) it was shown that relations between altitude and temperature, current velocity, and dominant substrate particle size were characterised by $\mathrm{r}^{2}=0.84,0.26$, and 0.29 respectively (exponential regressions, $P<0.001$, Fig. 2 in Beketov, 2008a). Nevertheless, broad altitudinal ranges cannot imply broad ecological requirements in total (i.e., species ecological niche), as altitude-independent factors were not considered here.

Although it is reasonable to expect a positive relationship between species niche breadth and range size, the empirical evidences for such relationship are poor (Gaston and Blackburn, 2000). Some studies have confirmed that species having a broader range of ecological requirements can occupy larger areas (e.g., Kessler, 2002; Illera et al., 2006), but some other have not (e.g., Burgmann, 1989; Gregory and Gaston, 2000). The practical complication that precludes comparison of different species niches is that the niches are $n$-dimensional (Hutchinson, 1957), with very high number of various requirements. Therefore, it is 
hard (if not impossible) to combine these requirements to provide a measure of niche breadth for meaningful comparison between species (Gaston and Blackburn, 2000).

The present study explicitly showed a negative relationship between species range size and altitude-dependent factors in the river system. This, of course, does not imply a negative relationship regarding the entire species niche. The wide altitudinal ranges found for the East Palaearctic mayflies can be explained by the Rapoport effect (Rapoport, 1982; Stevens, 1989, 1992), which was recently detected by the author in altitudinal distribution of mayflies using the same data set as used here (Beketov, 2009). The Rapoport effect is an increase in breadth of altitudinal/latitudinal ranges of species with increasing altitude/latitude. However, mechanisms determining the Rapoport effect itself remain to be revealed, although a number of reasonable explanations have been proposed already (Brown, 1995; Gaston and Blackburn, 2000; Hernández Fernández and Vrba, 2005; Parmesan et al., 2005; Almeida-Neto et al., 2006).

\section{Comparison with previous studies}

Results of the present study can be compared with the works by Ribera and Vogler (2000), Ribera et al. (2003), and Hof et al. (2006, 2008). These authors revealed that geographical distributions of aquatic beetles (Ribera and Vogler, 2000), dragonflies (Hof et al., 2006), and aquatic animals in general (Hof et al., 2008) depend on species dispersal propensity, which in turn depend on the species' ecological requirements. Specifically, they showed that in Europe species inhabiting standing-water habitats have larger geographical ranges than species inhabiting running waters (for dragonflies also in North America). This pattern was explained by the fact that lentic habitats are less stable and predictable in historical view than lotic ones, and therefore lentic species need some dispersal propensity to survive on an evolutionary time scale (see also Dobson and Frid, 1998).

The present study, like the above-mentioned publications, demonstrated that geographical ranges of species depend on their ecological requirements. However, in the present work the patterns of cross-continental distribution are thought to be determined by location and properties of the West Siberian Lowland and directly by species' ecological requirements, but not by the species' dispersal propensity as has been shaped by such requirements during evolution. The reason is that in this study only lotic habitats were considered, and therefore the evolutionary effect of habitat stability on dispersal propensity is excluded. Nevertheless, two of the East Palaearctic potamophilic mayflies considered here also inhabit standing-water habitats $(C$. dipterum, $C$. horaria, Table 1$)$, and therefore wide distribution of these species can additionally be determined by the evolutionary mechanisms explained above (Ribera and Vogler, 2000; Ribera et al., 2003; Hof et al., 2006, 2008).

\section{Representativeness of the data set}

The data set analysed in the present study includes 47 species and thus comprises $82.5 \%$ of the overall species number recorded from the studied territory $(57$ species, Beketov and Kluge, 2003; Beketov, 2004a, 2005a, 2007; Beketov and Godunko, 2005). The actual number of mayfly species in the studied territory is obviously not much higher because of the relatively severe climatic conditions. Thus, in northern Europe 53, 46, and 60 species only were recorded for Finland, Norway, and Sweden respectively (Euro-limpacs Consortium, 2006). The 47 species considered in the present study certainly represent the Trans- and East Palaearctic mayflies having wide geographical distributions, for which an analysis of cross-continental distribution patterns is applicable. Thus, the present study includes 15 out of 23 Transpalaearctic species included in the relatively comprehensive key by Kluge (1997). Also, the present data set obviously covers the majority of those East Palaearctic species, which are distributed westward to the eastern border of the West Siberian Lowland, as this region (i.e., the study region) was sampled extensively. Nonetheless, further investigations are necessary to provide more detailed information on geographical and altitudinal distribution of the Palaearctic mayflies.

Concerning possible biases associated with measuring the species altitudinal distribution of widely distributed species in a small part of their geographical range (e.g., Hortal et al., 2008), pronounced geographical variability in species altitudinal distribution and related ecological characteristics is highly unlikely, because literature records from Europe (Euro-limpacs Consortium, 2006) and Asia (Kluge, 1997; Zaika, 2006) are in agreement with the altitudinal records analysed in the present study.

\section{Conclusions}

The present study showed that patterns of crosscontinental distribution of palaearctic mayflies are largely determined by the species' ecological characteristics and the vast environmental barrier represented by the West Siberian Lowland. In particular, it was shown that most of the East Palaearctic mayfly species inhabit high-altitude streams, and this lowland can be an environmental barrier preventing their westward dispersal and therefore precluding full mixing of the East and West Palaearctic faunas. The Transpalaearctic mayfly species, in contrast, were shown to inhabit low-altitude sections of the river continuum, and therefore the West Siberian Lowland cannot be a barrier preventing their cross-Eurasian distribution. Nevertheless, the present study cannot rule out possible alternative hypotheses explaining distribution of East Palaearctic mayflies, as altitudinal ranges of some of these species do not fall out of the elevation range of the West Siberian Lowland.

The studied mayflies were shown to be distributed in accordance with their altitudinal ranges. However, broad 
altitudinal ranges do not imply wide geographical distribution. Thus, the East Palaearctic species, which by definition have narrower geographical distribution than the Transpalaearctic species, have, on average, much broader altitudinal ranges than the Transpalaearctic species.

Acknowledgements. The study was supported by the European Union (project INTERACT, Marie Curie IIF contract no. MIF1-CT-2006-021860) and the Helmholtz Association of German Research Centres (project ECOLINK, HRJRG-025).

\section{References}

Adams J.M. and Woodward F.I., 1989. Patterns in tree species richness as a test of the glacial extinction hypothesis. Nature, 339, 699-701.

Allan J.D., 1995. Stream ecology: structure and function of running waters, Chapman and Hall, London, UK, 400 p.

Almeida-Neto M., Machado G., Pinto-da-Rocha R. and Giaretta A.A., 2006. Harvestman (Arachnida: Opiliones) species distribution along three Neotropical elevational gradients: an alternative rescue effect to explain Rapoport's rule? J. Biogeogr., 33, 361-375.

Banarescu P., 1990. Zoogeography of fresh waters. General distribution and dispersal of freshwater animals, AULA Verlag, Wiesbaden, Germany.

Beketov M.A., 2004a. New data on mayflies (Ephemeroptera) of South-West Siberia. Euroas. Entomol. J., 3, 25-27.

Beketov M.A., 2004b. Different sensitivity of mayflies (Insecta, Ephemeroptera) to ammonia, nitrite and nitrate: linkage between experimental and observational data. Hydrobiologia, 528, 209-216.

Beketov M.A., 2005a. Species composition of stream insects of northeastern Altai: mayflies, caddisflies, and stoneflies (Ephemeroptera, Plecoptera, and Trichoptera). Euroas. Entomol. J., 4, 101-105.

Beketov M.A., 2005b. Mayflies, stoneflies, and caddisflies (Ephemeroptera, Plecoptera, and Trichoptera) of water streams of Sema river basin, Altai Mountains. In: Kryukov V.Yu. and Beketov M.A. (eds.), Proceedings of the conference "Autumn Zoological Sessions 2005", NGPU, Novosibisrk, Russia, 47-50.

Beketov M.A., 2006. Caddisflies (Trichoptera) of south-western Siberia: new zoogeographical records, aquatic habitat preferences and flight periods. Braueria, 33, 13-16.

Beketov M.A., 2007. New records of mayflies and stoneflies (Ephemeroptera, Plecoptera) in South-West Siberia. Euroas. Entomol. J., 6, 387-388.

Beketov M.A., 2008a. Community structure of Ephemeroptera in Siberian streams. Entomol. Sci., 11, 289-299.

Beketov M.A., 2008b. First data on caddisflies (Trichoptera) of streams of northern middle Siberia, Russia. Entomol. News, 119, 299-302.

Beketov M.A., 2009. Rapoport effect is detected in a river system and is based on nested organization. Global Ecol. Biogeogr., 18, 498-506.

Beketov M.A. and Godunko R.J., 2005. Baetis khakassikus n. sp., a new species of the subgenus Rhodobaetis Jacob, 2003 from Middle Siberia, Russian Federation (Ephemeroptera: Baetidae: Baetis). Genus, 16, 7-12.

Beketov M.A. and Kluge N.J., 2003. Mayflies of Southwestern Siberia, Russia (Ephemeroptera). Opusc. zool. flumin., 211, $1-6$.

Beketov M.A. and Liess M., 2008. An indicator for effects of organic toxicants on lotic invertebrate communities: Independence of confounding environmental factors over an extensive river continuum. Environ. Pollut., 156, 980-987.

Bernatchez L. and Wilson C.C., 1998. Comparative phylogeography of Nearctic and Palearctic fishes. Mol. Ecol., 7, 431452.

Bilton D.T., Freeland J.R. and Okamura B., 2001. Dispersal in freshwater invertebrates. Annu. Rev. Ecol. Syst., 32, 159-181.

Bonada N., Murria C., Zamora-Munoz C., El Alami M., Poquet J.M., Punti T., Moreno J.L., Bennas N., Alba-Tercedor J., Ribera C. and Prat N., 2009. Using community and population approaches to understand how contemporary and historical factors have shaped species distribution in river ecosystems. Global Ecol. Biogeogr., 18, 202-213.

Brodsky K.A., 1980. The mountain torrent of Tien-Shan: a faunistic-ecology essay, Monographiae Biologicae, Vol. 39, Junk, The Hague, The Netherlands.

Brown J.H., 1995. Macroecology, University of Chicago Press, Chicago, USA.

Burgman M.A., 1989. The habitat volumes of scarce and ubiquitous plants - a test of the model of environmentalcontrol. Am. Nat., 133, 228-239.

Dobson M. and Frid C., 1998. Ecology of aquatic systems, Longman, Harlow, UK.

Dynesius M. and Jansson R., 2000. Evolutionary consequences of changes in species' geographical distribution driven by Milankovitch climate oscillations. P. Natl. Acad. Sci. USA, 97, 9115-9120.

Ehlers J. and Gibbard P.L., 2007. The extent and chronology of Cenozoic Global Glaciation. Quatern. Int., 164-165, 6-20.

Euro-limpacs Consortium, 2006. Freshwaterecology.info-The Taxa and Autecology Database for Freshwater Organisms, Version 3.0, www.freshwaterecology.inf

Gaston K.J., 1994. Rarity, Chapman \& Hall, London, UK.

Gaston K.J. and Blackburn T.M., 2000. Pattern and process in macroecology, Blackwell Science Ltd., Oxford, UK.

Gotelli N.J. and Colwell R.K., 2001. Quantifying biodiversity: procedures and pitfalls in the measurement and comparison of species richness. Ecol. Lett., 4, 379-391.

Gregory R.D. and Gaston K.J., 2000. Explanations of commonness and rarity in British breeding birds: separating resource use and resource availability. Oikos, 88, 515-526.

Hernández Fernández M. and Vrba E.S., 2005. Rapoport effect and biomic specialization in African mammals: revisiting the climatic variability hypothesis. J. Biogeogr., 32, 903918.

Hershey A.E., Pastor J., Peterson B.J. and Kling G.J., 1993. Stable isotopes resolve the drift paradox for Baetis mayflies in an arctic river. Ecology., 74, 2415-2520.

Hof C., Brändle M. and Brandl R., 2006. Lentic odonates have larger and more northern ranges than lotic species. J. Biogeogr., 33, 63-70.

Hof C., Brändle M. and Brandl R., 2008. Latitudinal variation of diversity in European freshwater animals is not concordant across habitat types. Global Ecol. Biogeogr., 17, 539-546. 
Hortal J., Jimenez-Valverde A., Gomez J.F., Lobo J.M. and Baselga A., 2008. Historical bias in biodiversity inventories affects the observed environmental niche of the species. Oikos, 117, 847-858.

Hutchinson G.E., 1957. Concluding remarks. Cold Spring Harbour Symposia on Quantitative Biology, 22, 415-427.

Illera J.C., Diaz M. and Nogales M., 2006. Ecological traits influence the current distribution and range of an island endemic bird. J. Biogeogr., 33, 1192-1201.

Illies J. and Botosaneanu L., 1963. Problèmes et méthodes de la classification et de la zonation écologique des eaux courantes, considérées surtout du point de vue faunistitique. Mitteilungen Internationale Vereinigung für Theoretische und Angewandte Limnologie, 12, 1-57.

Ioganzen B.G., 1953. Fish-production regions of West Siberia and their biological and production characteristic [in Russian]. Trudy Tomskogo gosudarstvennogo universiteta, $125,7-44$.

Jacobsen D., 2008. Low oxygen pressure as a driving factor for the altitudinal decline in taxon richness of stream macroinvertebrates. Oecologia, 154, 795-807.

Kessler M., 2002. Range size and its ecological correlates among the pteridophytes of Carrasco National Park, Bolivia. Global Ecol. Biogeogr., 11, 89-102.

Kovats Z.E., Ciborowski J.J.H. and Corkum L.D., 1996. Inland dispersal of adult aquatic insects. Freshwater Biol., 36, 265276.

Kluge N.J., 1997. Order mayflies - Ephemeroptera. In: Tsalolikhin S.J. (ed.), Key to the freshwater invertebrates of Russia and the adjacent lands, Vol. 3: Arachnids and lower insects [in Russian], Zool. Inst. Russ. Acad. Sci., St Petersburg, Russia, 176-220.

Kluge N.J., 2007. Review of Ameletidae (Ephemeroptera) of Russia and adjacent lands. Russian Entomol. J., 16, 245-258.

Lomolino M.V., Riddle B.R. and Brown J.H., 2006. Biogeography, Sinauer Associates, Sunderland, USA.

Milkov F.N. and Gvozdetskii N.A., 1976. Physical geography of USSR [in Russian], Gidrometeoizdat, Moscow, USSR.

Munzel U. and Hothorn L.A., 2001. A unified approach to simultaneous rank test procedures in the unbalanced oneway layout. Biometrical J., 43, 553-569.

Novikova E.A. and Kluge N.J., 1997. Mayflies (Ephemeroptera) of West Siberian Lowland and oil pollution. In: Landolt P. and Sartori M. (eds.), Ephemeroptera \& Plecoptera: BiologyEcology-Systematics, 269-274.

Parmesan C., Gaines S., Gonzalez L., Kaufman D.M., Kingsolver J., Peterson A.T. and Sagarin R., 2005. Empirical perspectives on species borders: from traditional biogeography to global change. Oikos, 108, 58-75.
R Development Core Team, 2004. R: a language and environment for statistical computing, R Foundation for Statistical Computing, Vienna, Austria.

Rapoport E.H., 1982. Areography. Geographical Strategies of Species, Pergamon, New York, USA.

Ribera I. and Vogler A.P., 2000. Habitat type as a determinant of species range sizes: the example of lotic-lentic differences in aquatic Coleoptera. Biol. J. Linn. Soc., 71, 33-52.

Ribera I., Foster G.N. and Vogler A.P., 2003. Does habitat use explain large scale species richness patterns in aquatic beetles in Europe? Ecography, 26, 145-152.

Rihter G.D., 1963. West Siberia. Natural conditions and natural resources of USSR [in Russian], Acad. Sci. USSR, Moscow, USSR.

Sokolov A.A., 1952. Geography of USSR [in Russia], Gidrometeoizdat, Leningrad, USSR.

Stevens G.C., 1989. The latitudinal gradient in geographical range: how so many species coexist in the tropics. Am. Nat., $133,240-256$.

Stevens G.C., 1992. The elevational gradient in elevational range: an extension of Rapoport's latitudinal rule to altitude. Am. Nat., 140, 893-911.

Tiunova T.M., 2007. Current state of investigations of mayflies (Ephemeroptera) of Far East and neighbouring territories. Euroas. Entomol. J., 6, 181-194.

Tshernova O.A., Kluge N.J., Sinichenkova N.D. and Belov V.V., 1986. Order Ephemeroptera-Mayflies. In: Ler P.A. (ed.), Key to the insects of Soviet Far East, Vol. I: Apterygota, Palaeoptera, Hemimetabola [in Russian], Nauka, Leningrad, Russia, 99-142.

Ward J.V., 1992. Aquatic Insect Ecology. 1. Biology and Habitat, Wiley, New York, USA.

Webb T. and Bartlein P.J., 1992. Global changes during the last 3 million years: climatic controls and climatic responses. Ann. Rev. Ecol. Evol. S., 23, 141-173.

Whittaker R.J., Nogués-Bravo D. and Araújo M.B., 2007. Geographical gradients of species richness: a test of the water-energy conjecture of Hawkins et al. (2003) using European data for five taxa. Global Ecol. Biogeogr., 16, 76-89.

Winterbourn M.J., Chadderton W.L., Entrekin S.A., Tank J.L. and Harding J.S., 2007. Distribution and dispersal of adult stream insects in a heterogeneous montane environment. Fund. Appl. Limnol., 168, 127-135.

Zaika V.V., 2006. Insects-rheophils (Insecta, Ephemeroptera, Trichoptera, Plecoptera) of Todzha hollow (Republic Tyva). In: Abstracts of Multiregional Conference of Entomologists of Siberia and Far East, 20-24 September 2006, Novosisbirsk, Russia, 69-71. 